\title{
Expert Evaluation of Ecological and Economic Risks of Implementing Engineering Innovations by Coal-Mining Enterprises Based on Fuzzy Logic
}

\author{
Elena Raevskaya ${ }^{1, *}$, Alexander Pimonov ${ }^{1,2}$ and Vladimir Mihailov ${ }^{1}$ \\ ${ }^{1}$ T.F. Gorbachev Kuzbass State Technical University, Kemerovo, 650000, the Russian Federation \\ ${ }^{2}$ Institute of Economics and Industrial Engineering, Siberian Branch of the Russian Academy \\ of Sciences, Novosibirsk, 630090, the Russian Federation
}

\begin{abstract}
The article is about a complex approach based on the method of analyzing hierarchies and using of fuzzy logics for assessment of risks deals with engineering innovations in coal-mining industry. This approach allows evaluating both quantitative and qualitative risk indicators of compared alternative innovative mechanisms and equipment, does not depend on a field of expertise, thus it makes possible to attract specialists with competencies in various fields of knowledge. Such kind of approach allows making a qualitative assessment of the situation on the basis of formalized logical conclusions, making decision making comfortable and accessible to any specialist. The proposed methodology is implemented as a part of a decision support system.
\end{abstract}

\section{Introduction}

Currently, coal industry enterprises occupy one of the leading places in terms of the number of negative factors associated with production activities and affecting the environment. In 2017 coal-mining enterprises of the Kemerovo region emitted pollutants into the air with a total weight of over 915 thousand tons. It is $61.5 \%$ of all stationary sources in the region. The total volume of wastewater discharged by these enterprises amounts to almost 288 million $\mathrm{m}^{3}$. The total amount of waste generated as a result of mining of all types of minerals for the period under review is 3.12 billion tons [1].

However, an analysis of the state of environmental protection measures in the regions of coal mining and processing shows [2] that at present most technical solutions and measures are aimed to neutralizing and eliminating the consequences of production activities, rather than eliminating the root causes and their sources.

Reducing the negative impact of coal industry enterprises on the environment is carried out through partial restoration of the disturbed natural state, which is achieved through land reclamation, clarification and purification of wastewater, dust and gas recovery by heat and power plants and others. These measures are ineffective, because they do not solve the

\footnotetext{
*Corresponding author:pag_vt@kuzstu.ru
} 
problems that cause negative phenomena, but only partially eliminate the consequences, which led to a sharp deterioration of the ecological situation in the regions and large economic costs.

One of the main reasons for this situation is the untimely renovation of outdated low-efficiency mining equipment. Drilling equipment is used in extremely difficult conditions, complicated by the action of high static, dynamic loads on the actuators, the presence of abrasive and aggressive fluids under high pressure. In order to work in such conditions, it is necessary to create construction materials taking into account the entire list of factors that adversely affect the static, long-term strength, wear resistance and corrosion resistance of the working surfaces of machines and tools.

Thus, the question of the need for innovative machines and mechanisms to reduce a negative factor with the aim of its further exclusion becomes urgent. This, in turn, compels business leaders and authorities to pay special attention to the development and implementation of innovative processes in enterprises. However, innovation processes are accompanied by a high degree of risk associated with the implementation of the introduced innovation [3]. So, in modern conditions of tightening national environmental legislation and increasing the sensitivity of the main technical and economic indicators of an enterprise to its environmental and economic characteristics, the process of managing environmental and economic risks is particularly relevant.

The infrastructure of coal-mining enterprises is based on the integrated functioning of structural units in various fields of activity. Managers constantly face multidirectional tasks, decisions on which cannot be made using the same factors and models (comparison of enterprises by the level of investment attractiveness, evaluation of the effectiveness of mines, open-pit mines, coal processing plants, comparison of the competitiveness of coal grades and products of processing, comparison of the ecological state of the areas of mining operations, comparison of the technical level of mining machines and equipment, selection and evaluation of engineering and technical workers in the coal industry) [4].

Persons making decision on these tasks periodically face the need for an integrated assessment of the potential of innovative projects. When carrying out such an examination, a large number of functional indicators [5] (mining-geological, technological, technical, economic, ecological, social) must be taken into account, which may have a different nature quantitative and qualitative.

Thus, an important task is the formation of methods and algorithms for evaluating of ecological and economic risks of mining enterprises which allow taking into account the maximum possible number of factors associated with the implementation of innovation with minimal time, labor costs and a low proportion of subjectivity.

\section{Management of ecological and economic risks}

Many foreign and domestic scientists are engaged in research and management of ecological and economic risks. Thus, a common risk management algorithm was formed, consisting of the following mandatory steps:

1) identification of ecological and economic risks;

2) assessment of ecological and economic risks;

3) management of ecological and economic risks, including the development of directions for their reduction and elimination.

At the first stage, the main factors influencing the formation of environmental and economic risks and potential directions of possible losses from their implementation are determined. 
The main task of the second stage is to determine the economic damage and the probability of occurrence of a risk event. The complexity of this stage is the using of adequate methods of assessing economic damage and the likelihood of the implementation of environmental and economic risk, ensuring maximum reliability of the result.

Some authors detail the main stages of managing environmental and economic risks, highlighting in independent sections the definition of the structure of possible damage and graphical representation of the law of its distribution. In this case risk management is the formation of a prototype decision base, taking into account the control of risk exposure measures [5].

One possible option for investigating environmental and economic risks is the using of an approach consisting of four stages, where the first involves identifying the hazard, for assessing directly the environmental risk $[6,7]$.

Makhutov [8] differentiates strategic economic risks in the following way: local; object; local; regional; national; global; planetary. In the same paper, the authors calculate these risks in a classical way as the product of damage to the probability determined by the expert method. This approach should also be used for environmental and economic risks, which in many cases are transformed into traditional financial and economic risks.

An important problem of an adequate calculation of environmental and economic risks is the choice of a method for assessing the likelihood of an adverse event. In practice, the most common are three main methods [9]:

1) statistical - is based on the analysis of statistical data on similar events that occurred at similar sites in a given territory;

2) analytical - investigation of cause-effect relationships in the territorial production system, allowing to estimate the likelihood of risk occurrence as a complex phenomenon;

3) expert - is based on an assessment of the likelihood of adverse events by analyzing the results of a survey of experts.

For the most qualitative and accurate evaluation of the probability of occurrence of adverse events, it is necessary to use all methods simultaneously with checking the convergence of the results. A number of specialists believe that in addition to the above methods, math simulation ensures greater reliability of the result obtained [9].

Some experts [10] interpret zones of environmental and economic risk as a normal distribution, analogous to depicting speculative risks in the financial sector, when any deviation from the "normal" situation is viewed as a risk event (profit, loss, gain, loss, etc.).

In accordance with this approach, the following differentiation of environmental and economic risks is presented with the possible probability of their occurrence:

1) is critical with probability $0.00-0.19$;

2) dangerous with probability $0.20-0.36$;

3) allowable with probability $0.37-0.62$;

4) acceptable with probability $0.63-0.79$;

5) background with probability $0.80-1.00$

Practical application of the theory of ecological and economic risks is reflected in the analysis of the company's environmental and economic indicators [11-12], when one of the simple options for assessing environmental and economic risks is to determine the relative weight of fees for excess environmental impact in the overall value of the fee. Analysis of the data of large chemical enterprises has shown that this value can reach $90 \%$, characterizing the ineffectiveness of the conducted environmental policy and adversely affecting the company's technical, economic and financial indicators, reducing its profit. Another aspect of this problem is the inadequate rationing of the potential negative load on the environment, where compliance with standards is technologically impossible.

Estimation of environmental and economic risk can also be simplified by means of a risk factor $(K R)$ : 
$E D$ - economic damage from negative impact on the environment, ruble;

$P$ - payment for negative impact on the environment, ruble. Areas of risk factor values are presented taking into account the considered risk zones:

1) neglectful - to 0.2 ;

2) acceptable $0.2-0.5$;

3) critical $0.5-1.0$;

4) unacceptable - upper 1.0.

\section{Methodology for risk evaluation based on fuzzy logic}

The analysis of the main approaches to the study and assessment of ecological and economic risks has shown that, despite the variety of scientific papers on this issue, the management algorithm must necessarily include elements such as identification, assessment and measures to reduce or eliminate risks. Another classic problem in the management of ecological and economic risks is the search for adequate methods for determining the likelihood of occurrence of a risk event, ensuring maximum reliability of the result obtained.

Thus, the analysis of the problem has shown that there is no universal formalized methodology which would allow a qualitative effective evaluation of environmental and economic risks. Therefore, there is a need to find a method, which would allow an unlimited number of indicators to be used in order to assess the likelihood of risk occurrence, and in addition would make it possible to make estimates on the basis of indicators having a different nature - quantitative and qualitative.

It should be noted that for the evaluation of risk it is advisable to use not only numerical methods of data processing [13], but also to carry out a purely qualitative assessment of the situation on the basis of logical conclusions, presenting the obtained quantitative values of variables as some linguistic parameters [14], in combination with the method of analyzing the hierarchies of T. Saati [15], which allows you to rank the compared alternatives and conduct their pairwise comparison for each possible type of risk.

The advantages of using this approach include the possibility of using the expert's experience. As one of the tools for supporting decision-making in a condition of uncertainty, one can use the apparatus of the theory of fuzzy sets. The basis of the theory of fuzzy sets is the production of fuzzy logical inferences, that is, the derivation of conclusions in the form of a fuzzy set, which corresponds to the current input values using a fuzzy knowledge base and fuzzy operations [13-15].

The proposed methodology for a comparative expertise of risks and determining degree of importance in comparison with each other is based on the definition of linguistic variables and their values for each type of risk, the probability of which arises in the compared alternatives.

The technique using the hierarchy analysis method and the fuzzy logic apparatus consists of four stages.

Stage1. Preliminary examination of the compared alternatives for all possible types of risk. The purpose of the preliminary examination is to exclude the obviously unlikely risks on the selection criteria, so that at the next, estimated stage, the experts do not have to assess almost impossible risks.

Stage 2. Using of the method of analysis of hierarchies (MAI) T. Saati [14].

Stage 3.Combination the criteria as fuzzy sets.

Stage 4. Ranking of variants on the basis of fuzzy set-criteria, which correspond to Bellman-Zadeh scheme. When assessing indicators, experts set the lower estimates pessimistic and the upper estimates - optimistic. Further processing of Fuzzy formulated 
opinions of experts is proposed to be carried out by dephasing of the obtained fuzzy partial estimates and their further processing in a dephased form [14]

Thus, the task of decision making under the given technique is as follows.

There is $\mathbf{V}=\{v 1, v 2, \ldots, v \mathrm{n}\}-$ a set of alternatives that are subject to multicriteria analysis;

$\mathbf{C}=\{c 1, c 2, \ldots, c m\}-$ a set of quantitative and qualitative types of risks by which alternatives are evaluated;

$\mathbf{B}=\{b 1, b 2, \ldots, b k\}-$ competence of estimates $\mathrm{k}$ of experts conducting experts' assessment.

The problem is to arrange the elements of the set $\mathbf{V}$ by the criteria from the set $\mathbf{C}$, taking into account the competence $\mathbf{B}$ of the expert estimates. For example, in the role of qualitative criteria for comparing alternatives, we will use wear resistance $\left(\mathrm{K}_{1}\right)$, air emissions $\left(\mathrm{K}_{2}\right)$, doping or material modification $\left(\mathrm{K}_{3}\right)$, presence of lining $\left(\mathrm{K}_{4}\right)$; personnel injury risk $\left(\mathrm{K}_{5}\right)$. In accordance with the above list of criteria, one can distinguish linguistic variables $X_{i j}$, where $i$ is the number of the alternative; $j$ is the type of risk.

We define the range for all linguistic variables as $U_{i}=[0,1]$ for $i=1,2,3,4 ; j=1,2$, $3,4,5$.

The sets of values of linguistic variables (term sets) for the fifth criteria are formulated as follows:

$\mathrm{T}\left(X_{i 5}\right)=$ very high risk of injury + high risk of injury + risk of injury is possible + typical risk of injury + low level of injury.

Further, the following stages of the examination are expected:

1) fuzzy variables of each term set are used as qualitative estimates of alternatives according to one of the criteria;

2) to obtain evaluation of the alternatives under review, the method of expert evaluation is applied and survey of the expert group is conducted;

3 ) the compatibility functions of linguistic variables are formed as fuzzy subsets $U_{i}=[0,1]$ of the following form, for example, for type of risk $\mathrm{K}_{3}$ :

$$
\begin{gathered}
M \text { (very high risk of injury) }=\int_{0}^{0.25}(1-4 u) / u \\
M\left(\text { high risk of injury) }=\int_{0}^{0.25}(4 u) / u+\int_{0.25}^{0.5}(-4 u+2) / u\right. \\
M\left(\text { risk of injury is possible ) }=\int_{0.25}^{0.5}(4 u-1) / u+\int_{0.5}^{0.75}(-4 u+4) / u\right. \\
M(\text { typical risk of injury })=\int_{0.5}^{1}(4 u-2) / u+\int_{0.75}^{1}(-4 u+4) / u \\
M\left(\text { low level of injury) }=\int_{0.75}^{1}(4 u-3) / u\right.
\end{gathered}
$$


4) using average estimates of alternatives for each of the criteria, a matrix of average estimates is formed;

5) in view of the fact that the criteria have different degrees of importance, their coefficients of relative importance are determined using the hierarchy analysis method, then the Eigen values of the matrix are calculated and the coefficients of the relative importance of the criteria are calculated;

6) a fuzzy set of estimates of the criteria given by experts is modified by raising to a power corresponding to the coefficient of relative importance of the criterion;

7) calculation is made of set $D$ needed for selection of the preferred alternative based on the Savage criterion $(\max (\min ))$. To do this, select the maximum value of the indicator from the minimum for each alternative. The alternative thus obtained is given preference in selecting a project for implementation [15].

Thus, the decision-making become formalized and eliminate subjectivity of experts.

\section{Conclusion}

Using of proposed methodology forms the decision-making procedure for assessing the possibility of occurrence of ecological and economic risks as a clear and formalized, excluding possible subjectivity, taking into account the views of various experts.

The developed methodology is as part of an decision support system which allows taking into account criteria of risk which can have a different nature - quantitative and qualitative, using the method of comparisons of T. Saati.

The developed software automates the decision-making process in tasks which are difficult to quantify to any numerical analysis, such as competitive selection of innovations for their subsequent implementation, makes possible a preliminary assessment of the possible benefits and risks associated with the implementation of the evaluated project, allows minimize the influence of the human factor, thereby increasing the objectivity of the decision. The practical importance of this paper is to increase the efficiency of ecological and economic analysis of the enterprise, aimed at supporting the adoption of environmentally-safe management decisions.

The proposed methodology is focused on a wide range of people, due to the professional specifics of the selection-related tasks, for example: managers, sociologists, politicians, researchers, jury members, etc. Due to a mechanism for taking into account the opinion of several experts, it is possible to use experience of specialists with competences in various fields knowledge, which will make the result of decision making more objective and qualitative.

The use of the approach can reduce intellectual and time costs during the deciding making on the implementation of innovations.

\section{References}

1. G.S. Trushina. Coal, The influence of the Kuzbass coal industry on the ecological and food security of the region, 10, 98 (2018)

2. Y.A. Fridman, G.N. Rechko, E.Y. Loginova, Journal of Mining Science, Route map for innovation development in coal-mining Kuzbass, 51:5, 924 (2015)

3. A.Pimonov, E.Raevskaya, T.Sarapulova, E3S WEB OF CONFERENCES 15, $01021(2017)$

4. Y.A. Friedman, G.N. Rechko, A.G. Pimonov, Regional Research of Russia, Competitive advantages and innovation in regional economies, 2:3, 206 (2012) 
5. S.G. Tyaglov, T.V. Kushnarenko, A.A. Khokhlov, M.A. Qeropyan, European Research Studies Journal, The development of cluster relations within the state and business structures in terms of strategy of non-primary sector import-substitution, 20:1, 198 (2017)

6. J.R. Olsen, J.H. Lambert, Y.Y. Haimes, Risk Analysis, Risk of extreme events under nonstationary conditions, 18:4, 497(1998)

7. T.M. Tikhomirova, A.G. Sukiasyan, Economy of Region, Modified estimates of human potential in the regions of Russian Federation taking into consideration the risks of health losses and social tensions, 4, 164 (2014)

8. N.A. Makhutov, M.M. Gadenin, Ecology and Industry of Russia, Ecological safety and ecological heritage in problems of national safety, 20:1, 47 (2016)

9. N. Tikhomirov, T. Tikhomirova, E. Khamitov, V. Ponomarev, European Research Studies Journal, Models of assessment of the influnce of insurance assets securitization on stability of mutual insurance societies, 20:2, 321 (2017)

10. A.D. Murzin, T.Y. Anopchenko, Asian Social Science, Economic-mathematical modeling of social and environmental risks management of projects of urbanized territories development, 10:15, 249 (2014)

11. I.A. Ageev, V.N. Burkov, V.I.Zinchenko, T.V. Kiseleva, Automation and Remote Control, Structural analysis of the time data series, 66:6, 995 (2005)

12. V.G. Mikhailov, N.N. Golofastova, T.V. Galanina, T.G. Koroleva, Ya.S. Mikhailova, IOP Conf. Ser.: Earth Environ. Sci., Environmental-economic assessment of generation, flow and efficiency of use of production and consumption waste, 50:1, 012038 (2017)

13. L.A. Zadeh, Information and Control, Fuzzy sets, 8:3, 338 (1965)

14. L.A. Zadeh, Information Sciences, Similarity relations and fuzzy orderings, 3:2, 177 (1971)

15.W. Yoram, T.L. Saaty, Management Science, Marketing applications of the analytic hierarchy process, 26:7, 641 (1980) 